have ever shown the least disposition to it; but it is also to be noted, that in three other brothers of these patients the peculiarity has not yet been developed, and these have all passed their twentieth year. In cases one and two, as in Mr. Lane's case, the blood seemed less disposed to coagulate than usual, and had the appearance of being mixed with water. Another peculiarity in both these cases, was the impatience, I may say the irritability, produced in both by any attempt to employ pressure : in both it caused throbbing of the parts and great distress, and was obliged to be abandoned. The fortunate result of case No. 2, was, perhaps, to be attributed more to a spontaneous coagulation of blood over the wound in a patient almost drained of the vital fluid, than to the means empluyed.

\section{RETAINED PLACENTA AFTER PREMATURE LABOUR.}

\section{To the Editor of The Lancet.}

SIR:-Should you think the following case of abortion, in which the placenta remained thirty-one days after the escape of the fotus, attended with an unusually apathetic condition of the uterus, likely to interest the numerous subscribers to your Journal, I shall feel obliged by your giving it publication. I am, Sir, yours, \&c.

Charles Ray.

Elizabeth-street, Eaton-square.

Mrs. G., atat 35, of naturally good health, and the mother of five children, believed herself more than three months pregnant on the 20th Sept., when she went to visit some friends at a distance from home; and either from having eaten too heartily of some rich and unusual food, which disagreed with the stomach, or from travelling by rail. way for the first time, during which she expressed considerable alarm, she on returning became extremely unwell, sick, and faint with lassitude, and had an ex traordinary feeling of coldness over the pubes, with a slight bearing.down sensation. These symptoms, attended with trifling fever, continued for several days; and on Thursday, October 1st, as she was making use of the thamber vessel at bedtime, she stated that, without any pain, something suddenly passed from her, which, on examination, proved to be a perfect foetus of about $5 \frac{1}{2}$ months, with about an inch of umbilical cord attached. From its appearance, the foetus must have been separated from the mother about $p$ ight or ten days, probably at the time of her excursion on Sept. 20th, as the epidermis was elevated and flocculent over a dark red cutis, and the surface was in some situations changed from its natural bue. At the time of the foetus passing, no coloured fluid escaped with it, for it floated in about a pint of a healthy straw-coloured fluid resembling urine; nor was there after, or during the night, any flow of a bloody character. She described herself as relieved from the cold sensation and bearing-down after the pas. sage of the foetus, and felt much more herself on the succeeding day, although no placenta had followed. Perfect quietude in bed was enjoined, with cool and spare diet. Very little discharge flowed during the next twenty-four hours, and that only tinged with redness; but on the Saturday severdl small coagulated pieces passed, and at in. tervals a considerable quantity of bloody fluid, fibrinous enough to stiffen the nap. kins, \&c. This oozing of a perfectly inoffensive discharge continued in an uncertain manner for the next week, sometimes almost colourless, at others strongly marked with blood, and every few days accompanied with small coagula, but at no time from the com. mencement was there the slightest expulsory pain. Upon examination, per vaginam, on Oct. 2d, the morning after the foetus had escaped, the parts were so rigid that it was with great difficulty the os ateri could be traced; this orifice was very slightly dilated, and felt firm and unyielding; no placenta had lodged in the vagina, nor could its po. sition be discovered. In ten days, another examination proved some alteration in the rigidity of the structures, which were then more faccid, and felt softer to the touch; the os uteri was dilated to about the size of a shilling, and was easily detected. As she objected very much to remaining in bed, I sanctioned her being loosely dressed, and sitting with her feet up; the general health did not seem to suffer materially; slight weakness, attributable to the discharge and a less generous diet, was expressed; the bowels were kept gently acted on by mild aperients, and no other medical treatment was considered necessary. After three weeks, the discharge, which had remained without any foetor, seemed to disappear; and the characteristics of health, as regards the mind and body, returned, although quietude, and a very light animal and regetable diet, was persevered in.

This apparent improvement continued during the fourth week, when, from some sudden domestic excitement on Thursday, the 29 th, a relapse of the hæmorrhage oc. curred. The horizontal position was again enforced, and infusion of roses, with an excess of sulphuric acid and small doses of opium, was administered every four hours until the succeeding day, when all discharge of a high colour had ceased, so that she again ventured upon the erect rectanguldr position, observing the least possible exertion. On Saturday, Oct. 31st, about 3, P. M., whilst rising from her chair, a sudden rush of fresh arterial blood escaped from 
her, and continued flowing in a stream for several ninutes, when syncope temporarily restrained the alarming and profuse discharge. On my visiting her shorlly after. wards, I was astonished at the large quantity of massive, bright blood upon the floor, besides a number of napkins, \&c., that appeared entirely saturated; extreme faintness, with a death-like pallor, continued; the pulse was small, feeble, and irregular; and she said a trifling, hot discharge seemed to jet forth at short intervals. Upon examination I found the os nteri much less rigid, and dilated to the size of about half-a-crown piece, the surrounding muscular structure was flaccid and unresisting, and the flooding had stayed, but no placenta could be detected. It appeared remarkable that not the slightest pain was manifested through. out the whole period of the case; and I especially noticed that no pain, sensibility, or shrinking, was evinced on any of the occasions I had to explore the condition of the os uteri.

Considering this frequent and profuse hæmorrhage as attended with alarm, 1 determined to hazard an attempt to dislodge the placenta; to effect this, I gave her, at six o'clock, a scruple of freshly-powdered secale cornutum, repeating the dose every half hour, for four times; at midnight this not having produced any evident advantage, and the hæmorrhage continuing unrestrained, in defiance of cold applications, plugging, \&c., I gave her a drachm of the tincture of opium; and in about twenty minutes after, endeavoured to ascertain satisfactorily the gituation of the placenta, and if possible to detach it from its connexion with the uterus. With much difficulty I passed two fingers through the os uteri, and immediately felt the placenta in its natural anterior situation, but firmly attached within the fundus of the uterus, and requiring cautious and considerable digital exertion to effect its sepa. ration, which upon removal proved to be entire, excepting a few breakings down of its substance by tie fingers during its detachment. After my placing a bandage tightly around the pelvis, and finding a cessation of hæmorrhage, she took some gruel, and requested to indulge the intolerable desire she had for sleep, and remained quiet for several hours. In the morning, Nov. 1st, I found her tranquil and free from fever, nor had there been any pain; a slightly coloured discharge continued, the urine had flowed freely, and only moderate tenderness existed. During the next few days she was kept perfectly quiet, and upon a spare regimen; the bowels were gently relieved, and with the discharge from the uterus a few coagula had passed. In ten days from this time, with the exception of debility, and a less vigorous countenance, she states herself to be recovered, and engages in most of the domestic duties she was accustomed to fulfil.

Upon examining the placenta after its removal, I noticed the ficetal surface was very pale, and appeared shrivelled, almost as thongh it had been preserved in spirit, without any remains of the umbilical cord, whilst the maternal surface exhibited an appearance of large healthy-looking granulations of a rose-pink colour; about an inch of its upper portion seemed to have been previously detached, and formed two small irregular masses filled with dark venous blood. Its weight soon after removal, with the little fluid that oozed from it into the basin into which it was placed, was $3 \frac{1}{4}$ oz. Dr. Blundell visited this patient twice with me, during the second and third weeks.

REPORT OF THE

\section{GENERAL LUNATIC ASYLUM, NOTTINGHAM.}

\section{THIRTIETH ANNUAL REPORT.}

IT must be gratifying to the friends of humanity to observe the successful progress of the numerous lunatic asylums established thronghout the country, with a view to the treatment of the maladies of the insane. These magnificent and enlightened institutions of modern times, that, co-operating in the march of science in other departments, hold out to the mentally alienated a jodicious medical and moral treatment. How great the contrast between these true hospitals for the afflicted and the so-named hospitals in which are still permitted to exist the most flagrant of abuses; whose walls, stained with the cruelties of years, sigh in being required to yield to the inroads of medical intelligence and humanity. Among the most important of the provincial establishments is the General Lunatic Asylum of Nottingham, in which the humane system, so warmly advocated in this Jourval, is ably pursued under the direction of Dr. Blake and Mr. Powell.

Mr. Enfield, the vice-president, in his report of the institution, observes :-

The increased and increasing number of the patients renders it necessary to provide in some mode additional accommodation, and the subject will require early and careful consideration.

The religions services continue to afford their beneficial influences. The average attendance of the patients on divine service during the year has been from 60 to 70 , and of the servants from 12 to 13 . 